\title{
EFEKTIVITAS MODEL POE2WE TERHADAP HASIL BELAJAR SISWA PADA MATERI ALAT OPTIK
}

\author{
*Heri Maulana Sidik \\ Universitas Siliwangi \\ herimaulanasidik@gmail.com
}

Ariq Nurmahmuddin

Universitas Siliwangi ariqq.nurmahmuddin417@gmail.com

*koresponden author
Abstrak - Penelitian ini bertujuan untuk mengetahui hasil belajar siswa menggunakan model POE2WE (Prediction, Observation, Explanation, Elaboration, Write and Evaluation) yang diterapkan dalam proses pembelajaran siswa pada materi alat optik. Penelitian ini merupakan penelitian observasi dan studi pustaka. Populasi penelitian observasi adalah seluruh siswa SMA kelas XI jurusan MIPA. Tujuan dari penelitian ini adalah, 1) untuk mengetahui seberapa efektif model POE2WE terhadap pembelajaran fisika di sekolah; dan 2) untuk mengetahui sebarapa efektif model POE2WE terhadap hasil belajar siswa pada materi alat optik. Sampel penelitian terdiri dari 10 orang siswa SMA kelas XI jurusan MIPA. Instrumen penelitian berupa angket dan tes pengetahuan yang dilakukan melalui media online berupa Google Forms dan Google Drive. Hasil analisis data menjelaskan bahwa Penerapan model POE2WE dalam pembelajaran fisika pada materi alat optik adalah: 1) Efektif diterapkan dalam pembelajaran di sekolah; dan 2) Efektif diterapkan dalam pembelajaran fisika pada materi alat optik dengan nilai rata-rata persentase $86 \%$ berkategori baik terhadap hasil belajar siswa melalui post test yang telah dilakukan.

Kata Kunci : Model POE2WE, Hasil Belajar Siswa, Alat Optik.

Abstract - This study aims to determine student learning outcomes using the POE2WE (Prediction, Observation, Explanation, Elaboration, Write and Evaluation) model which is applied in the student learning process on optical instrument material. This research is an observational research and literature study. The observation research population was all high school students in class XI Mathematics and Natural Sciences major. The objectives of this study were, 1) to determine how effective the POE2WE model is for learning physics in schools; and 2) to find out how effective the POE2WE model is on student learning outcomes in optical instrument material. The research sample consisted of 10 high school class XI students majoring in Mathematics and Natural Sciences. The research instruments were questionnaires and knowledge tests conducted through online media such as Google Forms and Google Drive. The results of the data analysis explained that the application of the POE2WE model in learning physics on optical instrument material is: 1) Effectively applied in school learning; and 2) Effectively applied in learning physics on optical instrument material with an average percentage value of $86 \%$ in good category towards student learning outcomes through post tests that have been carried out.

Keywords : POE2WE Model, Student Learning Outcomes, Optical Devices. 


\section{A. PENDAHULUAN}

Peran pendidikan dalam kehidupan sehari-hari dari tahun ke tahun begitu pesat dibutuhkan dan diperlukan. Sebab, dari pelbagai aspek, pendidikan adalah sarana untuk menyalurkan dan melestarikan keilmuan dan humaniora. Dalam pendidikan banyak sekali cara-cara yang harus ditempuh. Baik itu dari penyusunan silabus, Rancangan Pelaksanaan Pembelajaran (RPP), kegiatan belajar-mengajar (KBM), evaluasi pembelajaran dan sebagainya. Dari tahun ke tahun peningkatan mutu pendidikan di berbagai negara semakin mebaik, terutama di negara kita tercinta ini sudah kita rasakan dari mulai regulasi, fasilitas hingga anggaran pendanaan pendidikan pun semakin baik hari ke hari. Itu sebagai salah satu bukti bahwa pendidikan di Indonesia sudah menjadi hal yang penting ditempuh oleh semua kalangan masyarakat di Indonesia. Menurut Hasbullah (dalam Djamaluddin, 2014) menjelaskan bahwa dalam arti sederhana pendidikan sering kali diartikan sebagai usaha manusia untuk membina kepribadiannya sesuai dengan nilai-nilai di dalam masyarakat dan kebudayaannya. Dalam perkembangannya, istilah pendidikan atau paedagogic berarti bimbingan atau pertolongan yang diberikan secara sengaja oleh orang dewasa agar menjadi dewasa. Selanjutnya, pendidikan diartikan sebagai usaha yang dijalankan oleh seseorang atau kelompok orang lain agar menjadi dewasa atau mencapai tingkat hidup atau penghidupan yang lebih tinggi dalam arti mental.

Model pembelajaran POEW dikembangkan dari model pembelajaran Predict, Observe, Explain (POE) dan Think, Bicara, Tulis (TTW). Menurut White and Gystone (Nana, 2014) Model pembelajaran POE adalah model pembelajaran dengan proses pengembangan pengetahuan, yang dimulai dengan memprediksi solusi atas suatu masalah, dan kemudian dilanjutkan dengan melakukan percobaan untuk membuktikannya prediksi, dan akhirnya diakhiri dengan menjelaskan hasil percobaan. Strateginya model pembelajaran TTW diperkenalkan oleh Huinker dan Laughlin (1996) dalam Sillberman (1996). Ini terdiri dari tiga fase, yaitu: berpikir, berbicara, dan menulis. Pertama, peserta didik diberi masalah, dan mereka berpikir kemungkinan jawaban untuk masalah tersebut. Kemudian, peserta didik bekerja dalam kelompok untuk mendiskusikan masalah yang ada. Terakhir, peserta didik secara individual menulis hasilnya diskusi mereka dalam kelompok dalam bahasanya sendiri sehingga ia menguasai konsep yang dipelajari. Itu integrasi antara model pembelajaran POE dan model pembelajaran TTW memungkinkan peserta didik untuk aktif dalam proses pembelajaran. Ini memberikan kesempatan kepada peserta didik untuk membangun pengetahuan, untuk berkomunikasi pemikiran, dan untuk menulis hasil diskusi mereka sehingga peserta didik jauh lebih menguasai konsep yang akan mempengaruhi peningkatan hasil belajar. Penerapan model pembelajaran POEW yang berlaku masih kurang mengoptimalkan kemampuan siswa untuk memprediksi dan untuk memecahkan masalah yang diberikan. Kurangnya pengetahuan awal siswa menjadi kendala bagi pembentukan prediksi mereka. Prediksi yang dibuat oleh seorang siswa membutuhkan pengetahuan awal dan luas tentang suatu masalah. Selain, selama praktikum para siswa hanya memainkan peran mereka dalam pelaksanaan praktikum. Instrumen, bahan, dan ukuran percobaan disediakan oleh para guru. Hal ini membuat siswa 
tidak terlatih untuk memilikinya pemikiran kritis untuk merancang eksperimennya sendiri berdasarkan prediksi yang ia buat (Nana, 2014). Karena itu diperlukan untuk mengembangkan memprediksi, mengamati, menjelaskan, menguraikan, dan menulis (POE2WE) model pembelajaran, yang merupakan kolaborasi antara model pembelajaran POEW dan model konstruktivis. Model kolaboratif dapat memungkinkan siswa untuk membuat prediksi berdasarkan pengetahuan awal yang mereka miliki sehingga mereka dapat memecahkan masalah yang diberikan oleh guru mereka atau yang mereka temui dalam kehidupan sehari-hari mereka. Selain itu, para siswa diharapkan untuk menerapkannya dalam kehidupan sehari-hari mereka.

Model pembelajaran Prediction, Observation, Explanation, Elaboration, Write dan Evaluation (POE2WE) dikembangkan dari model pembelajaran POEW dan model pembelajaran Fisika dengan Pendekatan Konstruktivistik. Menurut Nana (2018) Model POE2WE merupakan model pembelajaran yang dikembangkan untuk mengetahui pemahaman siswa mengenai suatu konsep dengan pendekatan konstruktivistik. Model ini membangun pengetahuan dengan urutan proses terlebih dahulu meramalkan atau memprediksi solusi dari permasalahan, melakukan eksperimen untuk membuktikan prediksi, kemudian menjelaskan hasil eksperimen yang diperoleh secara lisan maupun tertulis, membuat contoh penerapan dalam kehidupan sehari-hari, menuliskan hasil diskusi dan membuat evaluasi tentang pemahaman siswa baik secara lisan maupun tertulis.

Menurut Nana, dkk. (2014), menyatakan bahwa Model pembelajaran POE2WE dapat menjadikan siswa sebagai subjek di dalam pembelajaran. Siswa aktif dalam menemukan suatu konsep melalui pengamatan atau eksperimen secara langsung, bukan dari menghafal buku materi maupun penjelasan dari guru. Model ini memungkinkan siswa aktif dalam proses pembelajaran, memberikan kesempatan kepada siswa untuk mengkonstrukssi pengetahuannya, mengkomunikasikan pemikirannya dan menuliskan hasil diskusinya sehingga siswa lebih menguasai dan memahami konsep yang akan berdampak pada peningkatan prestasi belajar siswa. Hal tersebut sesuai dengan pendapat Permatasari (Nana, 2018) bahma model ini memberikan kesempatan kepada siswa untuk mengkonstruksi pengetahuannya sendiri, melakukan pengamatan terhadap fenomena serta mengkomunikasikan pemikiran dan hasil diskusi sehingga siswa akan lebih mudah menguasai konsep yang di ajarkan.

Menurut Nana, dkk. (2014), menyatakan bahwa Penggabungan tahapan-tahapan pembelajaran model POEW dengan Pendekatan Konstruktivistik maka dapat di susun langkah-langkah pembelajaran model POE2WE. Menurut Nana (2014) secara terinci langkah-langkah atau sintaks pembelajaran model POE2WE sebagai berikut: a) Prediction, tahap prediction yaitu siswa membuat prediksi atau dugaan awal terhadap suatu permasalahan. Permasalahan yang ditemukan berasal dari pertanyaan dan gambar oleh guru yang ada di LKS/buku siswa sebelum siswa membuat prediksi. Pembuatan prediksi jawaban tahap Prediction pada model POEW identik dengan fase Engagement pada pendekatan konstruktivistik. Guru mengajukan pertanyaan yang dapat mendorong siswa untuk dapat membuat prediksi atau jawaban sementara dari suatu permasalahan. b) Observation, tahap observation yaitu untuk membuktikan prediksi yang telah di buat oleh siswa. Siswa diajak melakukan eksperimen 
berkaitan dengan masalah atau persoalan yang di temukan. Selanjutnya siswa mengamati apa yang terjadi, kemudian siswa menguji kebenaran dari dugaan sementara yang telah dibuat. Tahap Observation pada model POEW identik dengan fase Exploration pada pendekatan konstruktivistik. c) Explanation, tahap explanation atau menjelaskan yaitu siswa memberikan penjelasan terhadap hasil eksperimen yang telah dilakukan. Penjelasan dari siswa dilakukan melalui diskusi dengan anggota kelompok kemudian tiap kelompok mempresentasikan hasil diskusinya di depan kelas. Jika prediksi yang di buat siswa ternyata terjadi di dalam eksperimen, maka guru membimbing siswa merangkum dan memberi penjelasan untuk menguatkan hasil eksperimen yang dilakukan. Namun jika prediksi siswa tidak terjadi dalam eksperimen, maka guru membantu siswa mencari penjelasan mengapa prediksi atau dugaannya tidak benar. Tahap explanation identik dengan fase explanation pada pendekatan konstuktivistik. d) Elaboration, tahap elaboration yaitu siswa membuat contoh atau menerapkan konsep dalam kehidupan sehari-hari. Tahap elaboration di ambil dari pendekatan konstruktivistik. Tahap ini guru medorong siswa untuk menerapkan konsep baru dalam situasi baru sehingga siswa lebih memahami konsep yang di ajarkan guru. Tahap ini pengembangan dari pendekatan konstruktivistik. e) Write, tahap write atau menulis yaitu melakukan komunikasi secara tertulis,merefleksikan pengetahuan dan gagasan yang dimiliki siswa. Siswa menuliskan hasil diskusi dan menjawab pertanyaan yang ada pada LKS. Selain itu pada tahap write ini, siswa membuat kesimpulan dan laporan dari hasil eksperimen. Tahap ini merupakan pengembangan dari model TTW. f) Evaluation, tahap evaluation yaitu evaluasi terhadap pengetahuan, keterampilan dan perubahan proses berfikir siswa. Pada tahap ini siswa di evaluasi berupa lisan maupun tulisan.Tahap ini merupakan pengembangan dari pendekatan konstruktivistik.

Tabel 1. Kegiatan Pembelajaran Model Pembelajaran Model POE2WE

\begin{tabular}{|c|c|c|}
\hline Fase- fase & Kegiatan Guru & Kegiatan Peserta Didik \\
\hline Prediction & 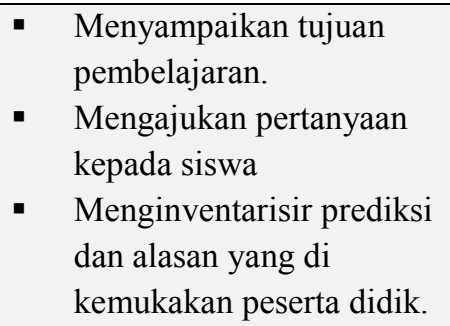 & $\begin{array}{l}\text { Memperhatikan penjelasan } \\
\text { dari guru. } \\
\text { Memprediksi jawaban } \\
\text { pertanyaan dari guru - } \\
\text { Mendiskusikan hasil } \\
\text { prediksinya }\end{array}$ \\
\hline Observation & 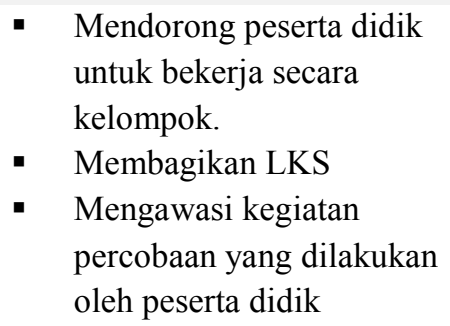 & $\begin{array}{l}\text { - } \text { Membentuk kelompok } \\
\text { - } \text { Melakukan percobaan } \\
\text { - } \text { Mengumpulkan data hasil } \\
\text { - } \text { percobaan } \\
\text { - } \text { Melakukan diskusi kelompok } \\
\text { percobaan }\end{array}$ \\
\hline
\end{tabular}




\begin{tabular}{|c|c|c|}
\hline Explanation & $\begin{array}{l}\text { - Mendorong peserta didik } \\
\text { untuk menjelaskan hasil } \\
\text { percobaan. } \\
\text { - Meminta peserta didik } \\
\text { pempresentasikan hasil } \\
\text { percobaannya } \\
\text { - Mengklarifikasikan hasil } \\
\text { percobaannya } \\
\text { Menjelaskan } \\
\text { konsep/definisi baru }\end{array}$ & $\begin{array}{l}\text { - } \\
\text { - } \quad \text { Mentang hasil percobaan } \\
\text { tentang gagasan baru } \\
\text { berdasarkan hasil percobaan. } \\
\text { - } \text { Menanggapi presentasi dari } \\
\text { kelompok lain. } \\
\text { - Konsep baru dari guru dapat } \\
\text { di terima }\end{array}$ \\
\hline Elaboration & $\begin{array}{l}\text { Memberi permasalahan } \\
\text { berkaitan dengan penerapan } \\
\text { konsep. } \\
\text { - Mendorong peserta didik } \\
\text { untuk menerapkan konsep } \\
\text { baru dalam situasi baru. }\end{array}$ & $\begin{array}{l}\text { Menerapkan konsep baru } \\
\text { dalam situasi baru atau } \\
\text { kehidupan sehari-hari. }\end{array}$ \\
\hline Write & $\begin{array}{l}\text { - Memberi kesempatan } \\
\text { kepada peserta didik untuk } \\
\text { mencatat }\end{array}$ & $\begin{array}{l}\text { Mencatat hasil penjelasan } \\
\text { dari guru dan diskusi } \\
\text { kelompok }\end{array}$ \\
\hline Evaluation & $\begin{array}{l}\text { - Mengajukan pertanyaan } \\
\text { untuk penilaian proses } \\
\text { - } \\
\text { Menilai pengetahuan } \\
\text { peserta didik } \\
\text { - Memberikan balikan } \\
\text { terhadap jawaban peserta } \\
\text { didik }\end{array}$ & $\begin{array}{l}\text { Menjawab pertanyaan } \\
\text { berdasarkan data } \\
\text { - } \\
\text { Mendemonstrasikan } \\
\text { kemampuan dalam } \\
\text { penguasaan konsep }\end{array}$ \\
\hline
\end{tabular}

(Sumber: Nana, 2018)

\section{B. METODE}

Penelitian ini merupakan penelitian deskriptif yang bertujuan untuk mendeskripsikan dan menganalisis tanggapan siswa terhadap penggunaan model pembelajaran POE2WE dalam pembelajaran fisika pada materi Alat Optik. Responden penelitian adalah 10 siswa kelas XI salah satu sekolah menengah atas di Kabupaten Tasikmalaya. Teknik pengumpulan data yang digunakan dengan kuesioner (angket) dan tes hasil belajar siswa (postest). Kuesioner merupakan tehnik pengumpulan data yang dilakukan dengan cara memberi seperangkat pertanyaan atau pernyataan tertulis kepada responden untuk menjawabnya. Setelah pembelajaran berakhir angket respon diberikan kepada responden (Arikunto, 2010). Angket tersebut berupa angket respon siswa setelah mengikuti pembelajaran model POE2WE. Persentase hasil belajar siswa siswa dihitung dengan rumus sebagai berikut:

$$
P \quad h a \quad b \quad S \quad=\frac{J \imath h S \text { y } \quad D \quad a B}{1(S \quad M \quad \text { ) }} \times 100 \%
$$

Hasil persentase respon tersebut diubah menjadi data kualitatif dengan kriteria sebagaimana ditunjukkan pada Tabel 2 berikut ini. 
Tabel 2. Kriteria Hasil Belajar Siswa dengan Menggunakan Model Pembelajaran POE2WE dalam Pembelajaran Fisika pada Materi Alat Optik.

\begin{tabular}{lc}
\hline \multicolumn{1}{c}{ Presentase Hasil Belajar Siswa $(\%)$} & Kategori \\
\hline $81,25<X<100$ & Sangat baik \\
$62,5<X<81,25$ & Baik \\
$43,75<X<62,5$ & Kurang Baik \\
\hline
\end{tabular}

Angket respon siswa yang diberikan sesaat setelah pembelajaran menggunakan model pembelajaran POE2WE. Data hasil tanggapan siswa ditunjukkan pada Tabel 3. Data Tanggapan Siswa. Berdasarkan tabel di bawah aspek 1 sampai 5 memuat respon ketertarikan siswa terhadap pembelajaran dengan masing-masing aspek memiliki skor 20. Aspek 6 sampai 9 memuat respon siswa terhadap kemudahan dalam memahami dan mempelajari materi dengan skor masing-masing aspek 25. Aspek 10 sampai dengan 14 memuat respon siswa dalam keaktifan dan keberanian mengungkapkan pendapat pada proses pembelajaran dengan skor masing-masing aspeknya yaitu 20. Pada dua aspek terakhir yaitu 15 dan 16 ini memuat tanggapan kemudahan siswa dalam menyimpulkan kegiatan pembelajaran dengan skor masing-masing aspeknya yaitu 50 .

Tabel 3. Data Tanggapan Siswa

\begin{tabular}{|c|c|c|}
\hline No & Aspek yang Dinilai & Skor \\
\hline 1 & $\begin{array}{l}\text { Pada awal kegiatan pembelajaran, penjelasan guru menarik } \\
\text { perhatian saya. }\end{array}$ & 20 \\
\hline 2 & Apersepsi sesuai dengan materi. & 20 \\
\hline 3 & Motivasi yang disampaikan menggugah semangat belajar & 20 \\
\hline 4 & Kegiatan pembelajaran lebih menarik dari pembelajaran biasanya & 20 \\
\hline 5 & Proses pembelajaran menambah semangat belajar. & 20 \\
\hline \multicolumn{2}{|c|}{ Skor Maksimum } & 100 \\
\hline 6 & Materi yang disampaikan dipahami dengan jelas & 25 \\
\hline 7 & Saya lebih mudah memahami materi pelajaran & 25 \\
\hline 8 & $\begin{array}{l}\text { Saya ingin membuat rangkuman materi pelajaran untuk } \\
\text { mempermudah memahaminya. }\end{array}$ & 25 \\
\hline 9 & $\begin{array}{l}\text { Pada saat pembelajaran, saya berusaha keras untuk memahami } \\
\text { materi pelajaran dengan baik. }\end{array}$ & 25 \\
\hline \multicolumn{2}{|c|}{ Skor Maksimum } & 100 \\
\hline 10 & $\begin{array}{l}\text { Saya mampu berperan aktif dalam pembelajaran saya dapat } \\
\text { bekerja sama dengan teman saat menyelesaikan permasalahan atau } \\
\text { melakukan penyelidikan. }\end{array}$ & 20 \\
\hline 11 & $\begin{array}{l}\text { Pada saat penyelidikan saya mampu mengidentifikasi variabel dan } \\
\text { mendeskripsikan hubungan antar variabel dengan baik. }\end{array}$ & 20 \\
\hline 12 & $\begin{array}{l}\text { Saya mampu melakukan penyelidikan menggunakan tahap-tahap } \\
\text { dalam keterampilan proses fisika dengan baik. }\end{array}$ & 20 \\
\hline 13 & $\begin{array}{l}\text { Saya dapat bekerja sama dengan teman saat menyelesaikan } \\
\text { permasalahan atau melakukan penyelidikan. }\end{array}$ & 20 \\
\hline 14 & Saya lebih berani mengungkapkan pendapat saya & 20 \\
\hline \multicolumn{2}{|r|}{ Skor Maksimum } & 100 \\
\hline 15 & Saya dapat membuat kesimpulan sebagai hasil akhir pembelajaran & 50 \\
\hline 16 & Saya dapat membuat laporan hasil penyelidikan dengan baik & 50 \\
\hline \multicolumn{2}{|c|}{ Skor Maksimum } & 100 \\
\hline
\end{tabular}




\section{HASIL DAN PEMBAHASAN}

Dalam hasil dan pembahasan, pertama langkah-langkah pembelajaran menggunakan Model POE2WE pada materi alat optik adalah sebagai berikut.

Tabel 4. Sintak Model Pembeljaran POE2WE Pada Materi Alat Optik

\begin{tabular}{|c|c|c|}
\hline Sintaks & Kegiatan Guru & Kegiatan Peserta Didik \\
\hline $\begin{array}{l}\text { Prediction } \\
\text { (Membuat dugaan } \\
\text { atau prediksi) }\end{array}$ & $\begin{array}{l}\text { - Guru menampilakan slide berupa } \\
\text { gambar dan meminta peserta didik } \\
\text { untuk membuat dugaan atau } \\
\text { prediksi tentang Alat Optik }\end{array}$ & $\begin{array}{l}\text { - Peserta didik membuat } \\
\text { dugaan atau prediksi } \\
\text { berdasarkan slide yang } \\
\text { ditampilkan oleh guru }\end{array}$ \\
\hline $\begin{array}{l}\text { Observation } \\
\text { (Melakukan } \\
\text { observasi atau } \\
\text { pengamatan) }\end{array}$ & $\begin{array}{l}\text { - Guru menberi intruksi agar peserta } \\
\text { didik bekerja secara kelompok } \\
\text { Guru meminta peserta didik untuk } \\
\text { mengidentifikasi lks yang } \\
\text { diberikan mengenai Alat Optik } \\
\text { Mengawasi berjalannya diskusi } \\
\text { kelompok peserta didik }\end{array}$ & 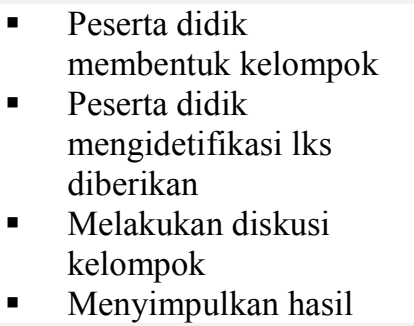 \\
\hline $\begin{array}{l}\text { Explanation } \\
\text { (Menjelaskan) }\end{array}$ & $\begin{array}{l}\text { - Guru meminta peserta didik untuk } \\
\text { mempresentasikan hasil diskusi } \\
\text { - Guru memverifikasi jawaban/hasil } \\
\text { diskusi peserta didik. }\end{array}$ & $\begin{array}{l}\text { Peserta didik } \\
\text { mengemukakan } \\
\text { pendapatnya } \\
\text { berdasarkan hasil } \\
\text { diskusi } \\
\text { Peserta didik } \\
\text { menanggapi presentasi } \\
\text { dari kelompok lain } \\
\text { Peserta didik } \\
\text { menanggapi penjelasan } \\
\text { dari guru }\end{array}$ \\
\hline $\begin{array}{l}\text { Elaboration } \\
\text { (Aplikasi konsep } \\
\text { dalam kehidupan } \\
\text { sehari-hari) }\end{array}$ & $\begin{array}{l}\text { - Guru mengaitkan materi yang } \\
\text { sedang dipelajari dengan agama } \\
\text { dan kehidupan sehari-hari. }\end{array}$ & 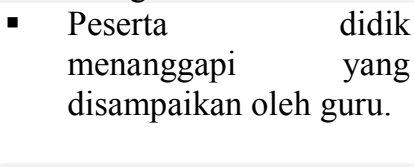 \\
\hline $\begin{array}{l}\text { Write } \\
\text { (Menuliskan hasil } \\
\text { diskusi) }\end{array}$ & $\begin{array}{l}\text { - Guru memberikan instruksi kepada } \\
\text { peserta didik untuk menuliskan } \\
\text { point-point penting tentang Alat } \\
\text { Optik dari hasil penjelasan guru } \\
\text { dan diskusi kelompok }\end{array}$ & $\begin{array}{l}\text { - Peserta didik mencatat } \\
\text { hasil penjelasan dari } \\
\text { guru dan diskusi } \\
\text { kelompok }\end{array}$ \\
\hline $\begin{array}{l}\text { Evaluation } \\
\text { (Evaluasi } \\
\text { terhadap } \\
\text { efektifitas fase- } \\
\text { fase sebelumnya) }\end{array}$ & $\begin{array}{l}\text { - Guru memberikan soal atau } \\
\text { menanyakan beberapa pertanyaan } \\
\text { tentang materi yang telah } \\
\text { dipelajari. }\end{array}$ & $\begin{array}{l}\text { - Peserta didik menjawab } \\
\text { pertanyaan atau soal } \\
\text { yang diberikan oleh } \\
\text { guru. }\end{array}$ \\
\hline
\end{tabular}

Kedua, setelah melakukan pembelajaran pada materi alat optik dengan menggunakan Model POE2WE, kemudian dilakukan post test untuk mengetahui hasil belajar siswa. Dengan hasil tes akhir siswa pada materi alat optik sebagai berikut.

Tabel 5. Hasil Tes Akhir Siswa pada Materi Alat Optik Menggunakan Model POE2WE

\begin{tabular}{cccc}
\hline No & Inisial & $\begin{array}{c}\text { Nilai Tes } \\
\text { Akhir }\end{array}$ & Kategori \\
\hline 1 & AN & 100 & Sangat Baik \\
2 & HS & 100 & Sangat Baik \\
3 & IM & 80 & Baik
\end{tabular}




\begin{tabular}{cccc}
4 & NS & 100 & Sangat Baik \\
5 & DN & 20 & Kurang Baik \\
6 & DHM & 100 & Sangat Baik \\
7 & DM & 100 & Sangat Baik \\
8 & YM & 60 & Cukup \\
9 & WS & 100 & Sangat Baik \\
10 & SDP & 100 & Sangat Baik \\
\hline Rata-rata Hasil Belajar Siswa & 86 & Baik \\
\hline \multicolumn{3}{c}{ Rata-rata Pesentase Hasil } \\
Belajar Siswa
\end{tabular}

Berdasarkan tes yang dilakukan terhadap 10 siswa yaitu dengan cara memberikan soal kepada siswa pada saat setelah pembelajaran mengenai materi pokok Alat Optik didapat rata-rata presentase hasil belajar siswa yaitu $86 \%$, dimana itu termasuk kategori baik. Dari presentase ada 7 siswa mendapat predikat sangat baik, 1 siswa mendapat predikat baik, 1 siswa predikat cukup dan 1 siswa dengan predikat kurang baik. Jadi, penerapan model POE2WE ini dalam pembelajaran fisika pada materi alat optik efektif digunakan.

\section{SIMPULAN}

Penerapan model POE2WE dalam pembelajaran fisika pada materi alat optik adalah sebagai berikut.

1. Efektif diterapkan dalam pembelajaran di sekolah.

2. Efektif diterapkan dalam pembelajaran fisika pada materi alat optik dengan nilai rata-rata persentase $86 \%$ berkategori baik terhadap hasil belajar siswa melalui post test yang telah dilakukan.

\section{DAFTAR RUJUKAN}

Arikunto, S. (2010). Dasar-dasar Evaluasi Pendidikan. Jakarta: PT. Bumi Aksara.

Djamaluddin, A. (2014). Filsafat Pendidikan. Istiqra: Jurnal Pendidikan dan Pemikiran Islam, 1(2) $150-156$

Mundilarto. (2012). Penilaian Hasil Belajar Fisika. Yogyakarta: UNY Press.

Nana, S., Akhyar, M., \& Rochsantiningsih, D. (2014). Pengembangan Pembelajaran Fisika SMA Melalui Elaboration Write and Evaluation (EWE) dalam Kurikulum 2013. In Seminar Nasional Pendidikan Sains.

Nana, S., Akhyar, M., \& Rochsantiningsih, D. (2014). The development of Predict, Observe, Explain, Elaborate, Write, and Evaluate (POE2WE) Learning Model in Physics Learning at Senior Secondary School. Development, 5(19).

Nana, Sudjana. (1995). Penilaian Hasil Proses Belajar Mengajar. Bandung: Remaja Rosdakarya.

Nana. (2014). Pengembangan Pembelajaran Fisika SMA Melalui Elaboration Write and Evaluation (EWE) Dalam Kurikulum 2013 (Surakarta: Disertasi UNS). 
Nana. (2018). Model Prediction, Observation, Explanation, Elaboration, Write dan Evaluation (POE2WE) Alternatif Pembelajaran Fisika di Era Revolusi Industri 4.0

Restami, M. P., Suma, K., \& Pujani, M. (2013). Pengaruh model pembelajaran POE (Predict-ObserveExplaint) terhadap pemahaman konsep fisika dan sikap ilmiah ditinjau dari gaya belajar siswa. Jurnal Pendidikan dan Pembelajaran IPA Indonesia, 3(1).

Sillberman, M. L. (1996). Active Learning (101 Cara Belajar Siswa Aktif). Penerjemah Raisul Muttaqien. Bandung: Nuansa Cendana. 